\title{
Role of Cyclic di-GMP in Xylella fastidiosa Biofilm Formation, Plant Virulence, and Insect Transmission
}

\author{
Subhadeep Chatterjee, ${ }^{1}$ Nabil Killiny, ${ }^{2}$ Rodrigo P. P. Almeida, ${ }^{2}$ and Steven E. Lindow ${ }^{1}$ \\ ${ }^{1}$ Department of Plant and Microbial Biology and ${ }^{2}$ Department of Environmental Science, Policy, and Management, University \\ of California, Berkeley 94720, U.S.A.
}

Submitted 7 March 2010. Accepted 26 June 2010.

Xylella fastidiosa must coordinately regulate a variety of traits contributing to biofilm formation, host plant and vector colonization, and transmission between plants. Traits such as production of extracellular polysaccharides (EPS), adhesins, extracellular enzymes, and pili are expressed in a cell-density-dependent fashion mediated by a cell-to-cell signaling system involving a fatty acid diffusible signaling factor (DSF). The expression of gene PD0279 (which has a GGDEF domain) is downregulated in the presence of DSF and may be involved in intracellular signaling by modulating the levels of cyclic di-GMP. PD0279, designated cyclic di-GMP synthase $A(\operatorname{cgs} A)$, is required for biofilm formation, plant virulence, and vector transmission. $\operatorname{cgs} A$ mutants exhibited a hyperadhesive phenotype in vitro and overexpressed gumJ, $h x f A, h x f B, x a d A$, and fim $A$, which promote attachment of cells to surfaces and, hence, biofilm formation. The mutants were greatly reduced in virulence to grape albeit still transmissible by insect vectors, although at a reduced level compared with transmission rates of the wild-type strain, despite the fact that similar numbers of cells of the $\operatorname{cgs} A$ mutant were acquired by the insects from infected plants. High levels of EPS were measured in $\operatorname{cgs} A$ mutants compared with wild-type strains, and scanning electron microscopy analysis also revealed a thicker amorphous layer surrounding the mutants. Overexpression of $\operatorname{cgs} A$ in a $\operatorname{cgs} A$-complemented mutant conferred the opposite phenotypes in vitro. These results suggest that decreases of cyclic di-GMP result from the accumulation of DSF as cell density increases, leading to a phenotypic transition from a planktonic state capable of colonizing host plants to an adhesive state that is insect transmissible.

Xylella fastidiosa is an important plant pathogen that causes disease in several economically important crops, including grape, citrus, almond, and coffee, as well as many horticultural shrubs and tree species (Hopkins and Purcell 2002). X. fastidiosa is restricted to the xylem vessels of plants and is transmitted by xylem-sap-feeding insects such as sharpshooter leafhoppers (Hemiptera, Cicadellidae) (Redak et al. 2004). Disease is associated with a progressive increase in the number of xylem vessels colonized in the plant, eventually reaching a point where water transport is compromised enough to initiate water

\section{S. Chatterjee and N. Killiny contributed equally to this work.}

Current address for S. Chatterjee: Centre for DNA Fingerprinting and Diagnostics, Nampally, Hyderabad 500001, India.

Corresponding author: S. E. Lindow; Telephone :+1.510.642.4174; Fax: +1.510 .642 .4995 ; E-mail: icelab@ berkeley.edu. scorching and other leaf symptoms that are likely associated with water stress.

Central to the biology of $X$. fastidiosa is a cell-to-cell signaling system encoded by a series of genes ( $r p f$ operon) that utilizes a fatty acid signal molecule known as diffusible signaling factor (DSF) to coordinate expression of several traits in a cell-density-dependent manner (Newman et al. 2004; Chatterjee et al. 2008c). Such traits include production of adhesins and extracellular polysaccharides (EPS), which are required for biofilm formation and insect transmission, as well as extracellular enzymes and type IV pili required for movement among xylem vessels (Meng et al. 2005; Roper et al. 2007; Killiny and Almeida 2009a and b). Density-dependent gene expression is apparently required because the traits that contribute to $X$. fastidiosa movement and growth within plants are incompatible with vector acquisition and subsequent inoculation into new hosts (Chatterjee et al. 2008a). For example, rpfF mutants of $X$. fastidiosa which are blocked in DSF production have lower expression of adhesins, are deficient in biofilm formation, and are unable to colonize insect vectors, yet they are hypervirulent in grape (Newman et al. 2004). In contrast, an rpfC mutant (a putative DSF receptor and phosphotransferase) overexpresses DSF and adhesins and is proficient in biofilm formation and insect colonization, while having reduced virulence in grape and transmission efficiency by the insect vectors (Chatterjee et al. 2008c). A model has been proposed that explains the contrasting phenotypes of the rpfF and rpfC mutants (Chatterjee et al. 2008a). In this model, DSF positively regulates synthesis of factors required for biofilm formation and vector transmission while suppressing traits such as endoglucanases, polygalacturonase, and type IV pili that are required for movement between and within xylem vessels. Analysis of an $r p f F$ mutant also indicated that PD0279, which encodes a GGDEF domain protein likely involved in the synthesis of cyclic di-GMP, was overexpressed compared with wild-type cells (Chatterjee et al. 2008c). Altered expression of PD0279 in an rpfF mutant suggests that cyclic di-GMP levels might play a role as a second messenger in coordinating the various traits that mediate plant colonization and insect transmission.

Cyclic di-GMP acts as an intracellular messenger that couples extracellular quorum sensing to the expression of virulence traits in several animal- and plant-pathogenic bacteria (D'Argenio and Miller 2004; Dow et al. 2006; Ryan et al. 2006b). Three protein domains (GGDEF, EAL, and HD-GYP) have been implicated in the modulation of cyclic di-GMP levels within cells, which then acts as an intracellular signaling molecule. The GGDEF domain proteins are diguanylate cyclases that synthesize cyclic di-GMP from two molecules of GTP, while the EAL and HD-GYP domain proteins have phos- 
phodiesterase activity and break down cyclic di-GMP to linear diguanylate (Jenal and Malone 2006; Romling and Amikam 2006; Ryan et al. 2006a). In Xanthomonas campestris pv. campestris, a pathogen of crucifers, cyclic di-GMP seems to participate as an intracellular signaling molecule that couples extracellular DSF signaling to the expression of virulence traits (Dow et al. 2006; Ryan et al. 2006a). Analysis of the genome sequence of Xylella fastidiosa (Temecula isolate) indicated the presence of three GGDEF or EAL domain-containing proteins (PD0279, PD1617, and PD1994). Interestingly, PD0279, denoted as cyclic di-GMP synthase A $(\operatorname{cgs} A)$ hereafter, has only a GGDEF domain but not an EAL domain, indicating that it may have a dedicated function for cyclic di-GMP synthesis. Given the close phylogenetic relationship between $X$. fastidiosa and Xanthomonads and the presence of such proteins that might modulate cyclic di-GMP levels, we hypothesized that DSFdependent signaling involves the modulation of cyclic di-GMP levels in $X$. fastidiosa.

Because cell surface features such as pili and afimbrial adhesins are under DSF regulation and play a particularly large role in the virulence and transmission of $X$. fastidiosa (Meng et al. 2005; Killiny and Almeida 2009a and b), and because cyclic di-GMP often is involved in the regulation of such traits in other systems (Tamayo et al. 2007; Jenal and Malone 2006), we investigated the role of this intracellular signal molecule in the biology of this important plant pathogen. We found that cyclic di-GMP levels in $X$. fastidiosa regulate gene expression and mediate DSF-dependent changes in behavior.

\section{RESULTS}

$\operatorname{cgs} A$ mutants have altered

surface-associated phenotypes in vitro.

To determine the possible role of CgsA in the biology of $X$. fastidiosa, the phenotypes associated with $\operatorname{cgs} A$ mutants was explored. $\operatorname{cgs} A$ encodes a 594-amino-acid protein with a GGDEF domain at the C-terminal region and is flanked by a $5^{\prime}$ gene encoding gamma glutamyl transferase ( $g g t)$ and a $3^{\prime}$ gene encoding a conserved hypothetical protein (Fig. 1). Two independent Tn5 insertional mutants of $\operatorname{cgs} A$, designated as Cgs20 and Cgs21, were made by allelic exchange mutagenesis. The transposon insertions in $\mathrm{Cgs} 20$ and $\mathrm{Cgs} 21$ are located in the 206th and 246th codon, respectively (Fig. 1).

Biofilm formation by the $\operatorname{cgs} A$ mutants as measured by adhesion to polystyrene culture plates was approximately fivefold more than the wild-type strain $\left(\mathrm{F}_{2,28}=27 ; P<0.0001\right)$ (Fig. 2A). This apparent increase in cell adhesiveness was also apparent in colonies recovered from solid medium; cells of the cgsA mutants were much stickier and more difficult to disperse in buffer than wild-type cells (data not shown). To confirm that disruption of the $\operatorname{cgs} A$ locus itself was responsible for the al-

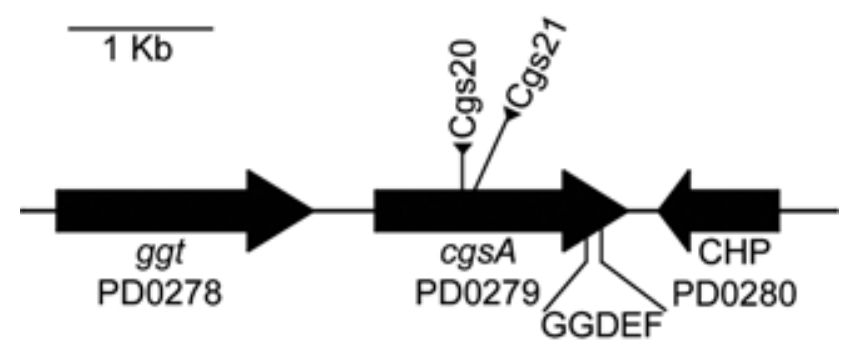

Fig. 1. Genomic organization of $\operatorname{cgs} A$ along with genes flanking the 594amino-acid open reading frame. PD0278 encodes for a gamma glutamyl transferase ( $g g t)$; PD0280 encodes a conserved hypothetical protein (CHP), which is located downstream of $\operatorname{cgs} A$. Closed triangles indicate the transposon insertion sites in mutants $\mathrm{Cgs} 20$ and $\mathrm{Cgs} 21$. tered adhesiveness of the mutants, we cloned $\operatorname{cgs} A$ as well as the upstream proximal 500-bp sequence into the broad-hostrange vector pBRR-5 to obtain $\mathrm{pSC} 22$, and introduced this plasmid into Cgs20. Interestingly, our attempt to express $\operatorname{cgs} A$ on this vector in Escherichia coli under the control of an isopropyl thio-D galactoside-inducible lac promoter failed due to its apparent toxicity to this host (data not shown). However, the severe growth defect could be partially rescued by addition
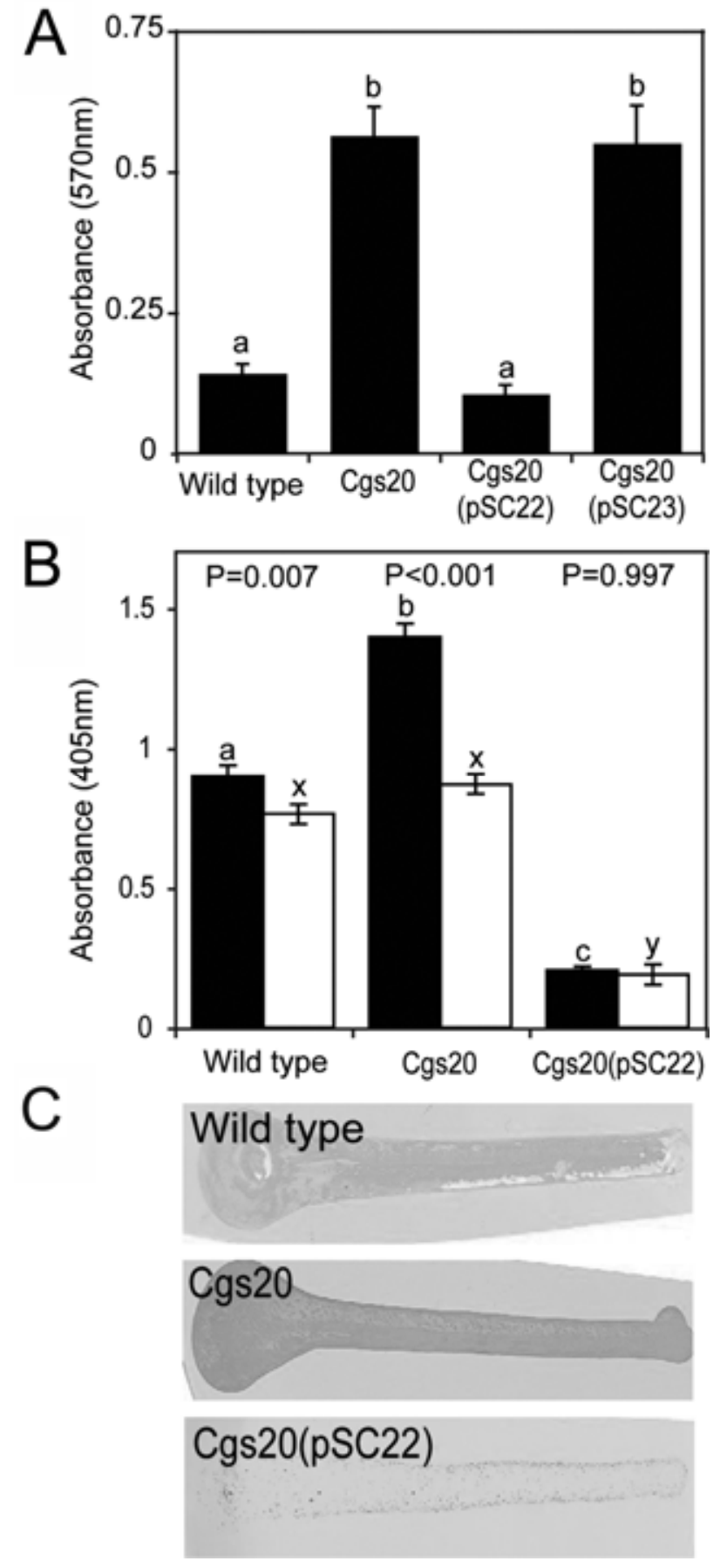

Fig. 2. In vitro phenotype of the wild type, $\operatorname{cgs} A$ mutant (Cgs20), Cgs20 (pSC22) (complemented strain), and Cgs20(pSC23) (empty vector). A, Biofilm formation on polystyrene surfaces. B, Extracellular polysaccharide production quantified immunologically; black and white columns represent unwashed and washed cells, respectively. C, Representative pictures of the glucan-specific dye Alcian blue 8GX staining of cell lawns printed on nitrocellulose membrane. Different letters above bars indicate statistically significant different strains $(P<0.01) ; P$ values above bars in $B$ indicate differences between treatments for each strain. 
of GTP (data not shown), suggesting that overexpression of $\operatorname{cgs} A$, which putatively has diguanylate cyclase activity, had depleted GTP levels within cells. Regardless, the $\operatorname{cgs}_{s} A$ mutant complemented with pSC22 (Cgs20(pSC22)) exhibited reduced attachment compared with $\mathrm{Cgs} 20$ and had similar attachment as the wild-type strain (Fig. 2A). No change in adhesion was observed when the empty vector pBRR-5 was introduced into the Cgs20 (Fig. 2A).

In addition to increased adhesiveness, EPS production by the $\operatorname{cgs} A$ mutant strains was much higher than the wild-type strain (Fig. 2B). Two-way analysis of variance (ANOVA) indicated differences between strains $(P<0.001)$, treatments (washed versus unwashed cells, $P<0.001)$, and an interaction between strains and wash treatment $(P<0.001)$. Protein A double-antibody sandwich enzyme-linked immunosorbent assay revealed that Cgs20 produced 1.7-fold more EPS than the wild type (Fig. 2B). In contrast, Cgs20(pSC22) produced fourfold less EPS than the wild type, suggesting that $\operatorname{cgs} A$ was overexpressed due to the presence of the wild-type $\operatorname{cgs} A$ in trans in a multicopy plasmid vector. Furthermore, 1.6-fold more EPS was recovered from unwashed Cgs20 compared with the washed cells of this mutant (Fig. 2B), suggesting that additionally produced EPS by Cgs20 is loosely associated with cells. EPS detected with a second method, using Alcian blue $8 \mathrm{GX}$ dye binding to $X$. fastidiosa cells attached to nitrocellulose membranes, also showed that the wild type and Cgs20 differed in EPS production. This dye is a glucan-specific stain that mainly detects mucopolysaccharides and glucoaminoglucans (Murray et al. 1994). Although heavy staining was observed in Cgs20 compared with the wild-type cells, much less staining was observed in Cgs20(pSC22) (Fig. $2 \mathrm{C}$ ), again indicating that the production of EPS was inversely proportional to the expression of $\operatorname{cgs} A$.

\section{Levels of $\operatorname{cgs} A$ transcription in $X$. fastidiosa are correlated with DSF-regulated gene expression.}

To investigate the role of cyclic di-GMP in regulation of pathogenicity and vector transmission traits and genes involved in DSF-mediated cell-to-cell signaling, we used quantitative real-time reverse-transcriptase polymerase chain reaction (qRT-PCR) to estimate mRNA abundance in $X$. fastidiosa strains having different levels of $\operatorname{cgs} A$ expression. $\operatorname{cgs} A$ was expressed approximately ninefold more in $\mathrm{Cgs} 20(\mathrm{pSC} 22)$ than in the wild-type strain (Table 1), likely due to plasmid copy number in the complementing strain. Interestingly, expression of rpfF was 2-fold higher in Cgs20 and 1.6-fold lower in Cgs20(pSC22) compared with the wild-type strain (Table 1). The overexpression of $r p f F$ in $\mathrm{Cgs} 20$ and its repression in Cgs20(pSC22) indicate that cyclic di-GMP levels mediate DSF production, whereas DSF itself ( $r p f F$-dependent) down-

Table 1. Relative quantification of gene expression regulated by $\mathrm{CgsA}$ by real-time reverse-transcriptase polymerase chain reaction ${ }^{\mathrm{a}}$

\begin{tabular}{lcc}
\hline & \multicolumn{2}{c}{$\begin{array}{c}\text { Fold change } \pm \text { standard error } \\
\text { in relation to the wild type (value of 1) }\end{array}$} \\
\cline { 2 - 3 } Gene & Cgs20 & Cgs20(pSC22) \\
\hline cgsA & $\ldots$ & $9.5 \pm 0.65$ \\
gumJ & $5.57 \pm 0.6$ & $0.13 \pm 0.1$ \\
fimA & $1.63 \pm 0.2$ & $0.01 \pm 0.03$ \\
hxfA & $4.9 \pm 0.7$ & $3.08 \pm 0.3$ \\
hxfB & $1.62 \pm 0.1$ & $0.52 \pm 0.1$ \\
xadA & $1.2 \pm 0.08$ & $0.7 \pm 0.12$ \\
rpfF & $2.42 \pm 0.25$ & $0.6 \pm 0.05$ \\
rpfC & $1.01 \pm 0.04$ & $1.1 \pm 0.07$ \\
pilY1 & $0.95 \pm 0.35$ & $0.01 \pm 0.09$ \\
\hline
\end{tabular}

a Amount of RNA relative to that in wild-type Xylella fastidiosa cells is equal to 1.0, and was normalized for population size using the $16 \mathrm{~S}$ ribosomal RNA gene as an endogenous control. regulates cgsA (Chatterjee et al 2008c). The expression of gumJ, fimA, $h x f A, h x f B$, and $x a d A$, all of which contribute to adhesion of cells to surfaces and to each other and, thus, to biofilm formation (Guilhabert and Kirkpatrick 2005; Meng et al. 2005; Feil et al. 2007; Killiny and Almeida 2009b), were higher in Cgs20 than in the wild-type strain (Table 1). As expected, these genes were downregulated in $\mathrm{Cgs} 20$ (pSC22).

\section{$\operatorname{cgs} A$ mutants are covered}

with an extracellular matrix that connects cells.

Surface features that influence adhesiveness oppositely modulate both plant virulence and insect transmissibility of $X$. fastidiosa; therefore, we investigated the surface of cells differing in $\operatorname{cgs} A$ expression by scanning and transmission electron microscopy. Cells of Cgs20 appeared to have a rough appearance with an extensive extracellular matrix (Fig. 3). This matrix obscured the cell surface compared with the wild-type cells (Fig. $3 \mathrm{~B}, \mathrm{H}$, and $\mathrm{K}$ ); it also seemed to connect Cgs20 cells together, forming a compact mass (Fig. 3H and K). Polarly located short pili that may connect cells were readily apparent in both Cgs20 cells as well as the wild-type strain (Fig. $3 \mathrm{H}$ and $\mathrm{K}$ ). In contrast, wild-type and $\mathrm{Cgs} 20(\mathrm{pSC} 22)$ cells had relatively smooth surfaces (Fig. 3A, C, D, and F). Although the average width of all cells was similar and approximately $400 \mathrm{~nm}$, the extracellular matrix formed an additional layer approximately $75 \mathrm{~nm}$ thick around Cgs20 (Fig. 3H). This matrix may be composed of the loosely associated EPS that was found to be more abundant in Cgs20 (Fig. 2B).

\section{$\operatorname{cgs} A$ is required for virulence in grape.}

The movement of $\operatorname{cgs} A$ mutants within grape and their ability to incite symptoms of Pierce's disease after mechanical inoculation were determined. Cgs20 and Cgs21 both caused approximately sixfold fewer symptomatic leaves compared with the parental strain at 12 weeks after inoculation $\left(\mathrm{F}_{2,74}=84,25 ; P<\right.$ 0.0001 ) (Fig. 4A). Although the incidence of disease increased with time in plants inoculated with either the wild type or the cgsA mutants, the number of symptomatic leaves on plants inoculated with the mutants was always lower (and statistically equal to each other) and restricted to leaves near the point of inoculation compared with plants inoculated with the wild-type strain (Fig. 4A). These results suggest that $\operatorname{cgs} A$ contributes to the ability of $X$. fastidiosa to migrate between and along xylem vessels, a prerequisite for disease causation.

\section{$\operatorname{cgs} A$ is required for efficient insect vector transmission of $X$. fastidiosa.}

Because $X$. fastidiosa is transmitted by vectors that must acquire and retain cells from infected plants, we investigated whether the changes in phenotype associated with blockage of cgs $A$ expression observed in vitro, and which reduced plant pathogenicity, also altered insect transmissibility. Transmission rates of Cgs20 and Cgs21 to new host plants were less than that of the wild-type strain $\left(\chi^{2}=13.125 ; \mathrm{df}=2 ; P=0.0014\right)$. Whereas the wild type was transmitted to $100 \%$ of the target plants, both Cgs20 and Cgs21 exhibited only 30\% transmission efficiency (Fig. 4B). However, the number of cells acquired by sharpshooters while feeding on infected plants did not differ among treatments. The average (log-transformed) number of $X$. fastidiosa cells in an insect head were $2.9 \pm 0.72$, $2.8 \pm 0.73$, and $3.2 \pm 1.07$ for $\mathrm{Cgs} 20, \mathrm{Cgs} 21$, and the wild-type strain, respectively; these population sizes were not statistically different $\left(\mathrm{F}_{2,14}=0.68 ; P=0.523\right)$. This indicates that cell acquisition from plants was not affected by $\operatorname{cgs} A$ expression. However, the experimental design did not allow for the separation between potential effects on cell retention in vectors versus inoculation (detachment) into plants that, altogether, con- 
tributed to lower vector transmission efficiency of Cgs20 and Cgs21. It is noteworthy that the genes upregulated in Cgs 20 (Table 1) have been positively associated with $X$. fastidiosa attachment to vectors (Killiny and Almeida 2009a and b). Thus, the $\operatorname{cgs} A$ mutants appear to be "sticky" and, thus, are readily acquired by the cuticular surface of vectors during feeding; however, their detachment from insects and subsequent colonization of a new plant might have been reduced, similarly to that observed with an $r p f C$ mutant that also exhibited elevated adhesiveness (Chatterjee et al. 2008c).
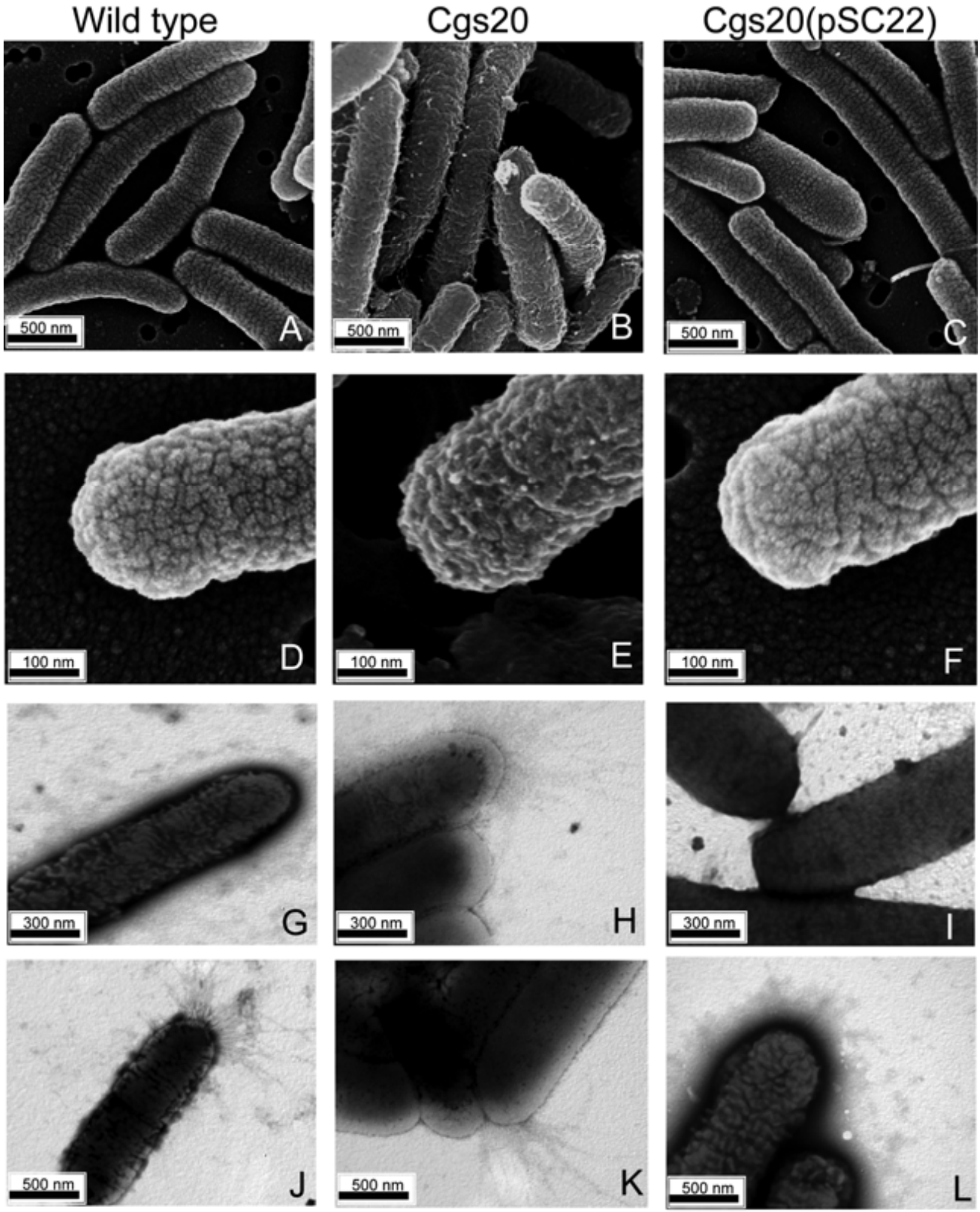

Fig. 3. Electron micrographs of Xylella fastidiosa cells. Scanning electron micrograph (SEM) of A and D, wild-type cells; $\mathbf{B}$ and $\mathbf{E}$, Cgs20 (cgsA mutant); and $\mathbf{C}$ and $\mathbf{F}, \mathrm{Cgs} 20$ (pSC22) (cgsA mutant with the complementing plasmid). Transmission electron micrographs (TEM) of $\mathbf{G}$ and $\mathbf{J}$, negatively stained $X$. fastidiosa cells of wild-type cells; $\mathbf{H}$ and $\mathbf{K}$, Cgs20 (cgsA mutant); and $\mathbf{I}$ and $\mathbf{L}, \mathbf{C g s} 20(\mathrm{pSC} 22)$ (cgsA mutant with the complementing plasmid). Note the presence of extra matrix in Cgs20 (B) and the polar group of pili in wild-type (J) and Cgs20 (K) cells attached to membrane. Extracellular matrix with netlike appearance is seen in the Cgs20 cells (B) but lacking in the complementation of this phenotype in Cgs20(pSC22) (C). Bars represent respective magnification in SEM and TEM. 


\section{DISCUSSION}

Although only recently appreciated, cyclic di-GMP is now recognized as a nearly ubiquitous bacterial secondary messenger involved in regulation of a wide range of processes such as virulence, EPS production, cell-to-cell signaling, biofilm formation, motility, and aggregative behavior (D'Argenio and Miller 2004; Romiling et al. 2005; Jenal and Malone 2006; Romiling and Amikam 2006; Ryan et al. 2006b; Tamayo et al. 2007). Three protein domains are involved in regulating cyclic di-GMP levels in a cell. The GGDEF domain, a constituent of diguanylate cyclase, is involved in cyclic di-GMP synthesis, while the EAL and HD-GYP domain proteins both have phosphodiesterase activity and are involved in the degradation cyclic di-GMP (D'Argenio and Miller 2004; Ryan et al. 2006a). Most often, these domains are associated with various sensory input domains that have been proposed to integrate various environmental signals such as extracellular cell-to-cell signaling. It has been proposed that quorum sensing and cyclic di-GMP signaling converge to regulate such community behaviors (Camilli and Bassler 2006). In general, high concentrations of cyclic di-GMP promote sessile behaviors such as biofilm formation, aggregation, attachment, and reduced motility in several pathogens, including Xanthomonas campestris pv. campestris (Ryan et al. 2006b), Vibrio cholerae (Simm et al. 2004; Lim et al. 2006), and Yersinia pestis (Bobrov et al. 2005). Intriguingly, a mutation in Arr of Pseudomonas aeruginosa, a protein with a conserved EAL domain and, thus, cyclic di-GMP phosphodiesterase activity, does not exhibit an increased biofilm formation phenotype as expected (Hoffman et al. 2005). This indicates that, although higher levels of cyclic di-GMP generally promote biofilm formation, this is not always the case. In a similar exception, we show here that blockage of the GGDEF protein CgsA, which presumably would lead to lower cyclic di-GMP levels, triggered increased adhesiveness and biofilm formation.

In a genetic reductionist approach, Solano and associates (2009) deleted all 12 GGDEF protein-encoding genes in Sal-

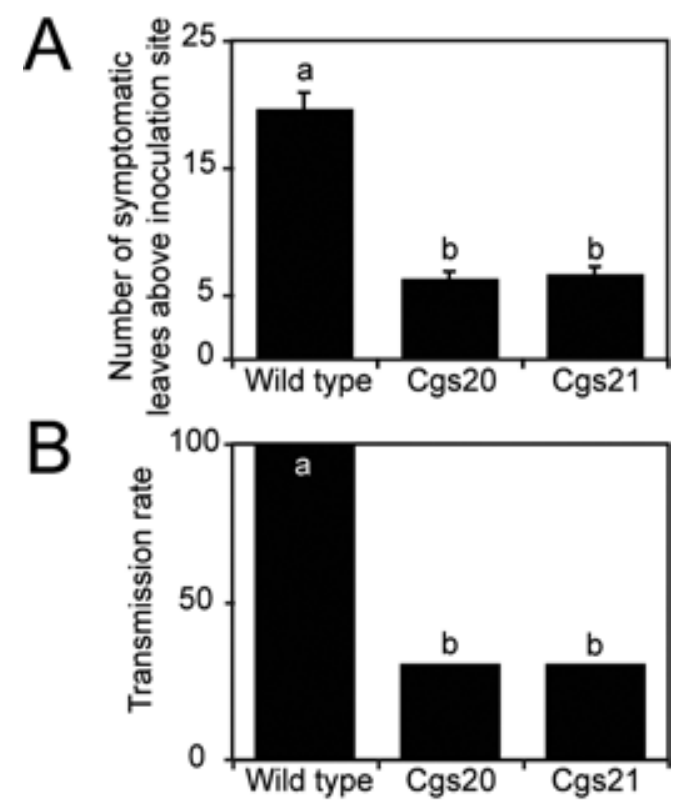

Fig. 4. $\operatorname{cgs} A$ mutants (Cgs 20 and $\mathrm{Cgs} 21)$ are affected in plant virulence and insect transmission. A, Severity of Pierce's disease symptoms on plants mechanically inoculated with Xylella fastidiosa wild type and mutants; different letters above bars indicate statistically significant different treatments $(P<0.01)$. B, Vector transmission efficiency of $X$. fastidiosa strains; different letters above bars indicate statistically significant different treatments $(P<0.025)$. monella enteritidis. This mutant exhibited the phenotypes associated with low cyclic di-GMP levels such as reduced biofilm formation and attachment; however, it also exhibited reduced motility. Individually restoring most GGDEF-domain proteins in this mutant strain rescued only a few of the phenotypes associated with low cyclic di-GMP levels. However, the GGDEF protein STM4551 rescued all of the phenotypes associated with low cyclic di-GMP levels. This suggests that temporal or spatial variation in levels of various proteins involved in cyclic di-GMP production or degradation could lead to phenotypic plasticity. The relatively small number of GGDEF proteins in Xylella fastidiosa may explain why CgsA apparently regulates a large number of phenotypes in this species.

Xanthomonas campestris pv. campestris and Xylella fastidiosa seem to share a system that links DSF-mediated cellto-cell signaling with intracellular signaling using cyclic diGMP but the outputs of this signaling differ. In Xanthomonas campestris pv. campestris, DSF is involved in activating the response regulator RpfG, which has an HD-GYP domain. $r p f G$ mutants of $X$. campestris pv. campestris are deficient in the synthesis of virulence traits such as EPS and extracellular enzymes, and exhibit a hyperaggregative phenotype that leads to deficiency in biofilm dispersal (Dow et al. 2003; Ryan et al. 2006a). In that system, DSF seems to activate RpfC (a hybrid DSF sensor) that, in turn, activates RpfG, leading to lower levels of cyclic di-GMP due to its phosphodiesterase activity; $r p f G$ mutants of $X$. campestris pv. campestris most likely have higher levels of cyclic di-GMP and exhibit a sessile, aggregated phenotype (Ryan et al. 2006a). Although DSF levels are also apparently linked to cyclic di-GMP levels in Xylella fastidiosa, the effect on biological traits is generally opposite to that in Xanthomonas campestris pv. campestris. In Xylella fastidiosa, cell-to-cell signaling mediated by DSF positively regulates factors required for biofilm formation and insect transmission but represses traits required for plant colonization (Newman et al. 2004). An opposing phenotype is observed in the DSF-overproducing $r p f C$ mutant of $X$. fastidiosa (Chatterjee et al. 2008c), which is similar to the $\operatorname{cgs} A$ mutants studied here.

Considerable complexity in integration of quorum sensing and modulation of cyclic di-GMP levels has been shown in both Xanthomonas campestris pv. campestris and V. cholerae (Camilli and Bassler 2006; Ryan et al. 2006b, 2010) and apparently also occurs in Xylella fastidiosa. However, there is no direct evidence that signaling molecules directly bind to GGDEF, EAL, or HD-GYP domain proteins and, thereby, modulate diguanylate cyclase or phosphodiesterase activity. In Xanthomonas axonopodis pv. citri, however, several GGDEF domain proteins interact with RpfC and RpfG; RpfF was also shown to interact with RpfC (Andrade et al. 2006; He et al. 2006). It is possible that protein-protein interactions of DSFmediated cell-to-cell signaling components and modulators of cyclic di-GMP levels regulate and fine tune DSF control of the cell-to-cell signaling transduction pathway as well as cyclic di-GMP levels in Xylella fastidiosa. Thus, cyclic diGMP may act as a co-repressor of DSF-mediated activation of virulence gene expression through interactions with RpfG. It has also been proposed that the interaction of GGDEF domain proteins with themselves (oligomerization state) or their interaction with other GGDEF, EAL, or HY-GYP proteins may regulate their diguanylate cyclase or phosphodiesterase activity (Chan et al. 2004; Ryan et al. 2006b, 2010; Tamayo et al. 2007). Clearly, further work is needed to differentiate these possible interactions.

The $\operatorname{cgs} A$-mediated regulation of EPS production in $X$. fastidiosa is consistent with its strong effect on virulence. EPS has been proposed to contribute to attachment, biofilm formation, and pathogenicity to plants in X. fastidiosa (Souza et al. 2006; 
Roper et al. 2007) (N. Killiny, unpublished data). The increased proportion of the EPS that can be washed from CgsA mutants observed may reflect the overexpression of EPS as a whole; excess EPS may be less intimately associated with the cell and, thus, more readily removed by washing. However, the extracellular matrix-like material that can be seen in electron micrographs of Cgs20 appears to link cells together. Such a phenotype might aid in biofilm formation in plants and might contribute to symptom development. The hyperadhesive phenotype of $\operatorname{cgs} A$ mutants of $X$. fastidiosa and their inability to migrate and cause disease in grape along with their low insect transmissibility can both be explained by upregulation of adhesins and EPS. This phenotype also explains the low frequency of transmission by insect vector harboring the CgsA mutants. The hyperadhesive phenotype of the CgsA mutants was similar to that of the DSFoverproducing mutant $r p f C$, which also exhibits increased biofilm formation in vitro, reduced movement along xylem vessels, and a deficiency in transmission to new host plants (Chatterjee et al. 2008b). Thus, within plants, lack of adhesiveness presumably facilitates movement and, thus, disease whereas adhesiveness is required for vector transmission. Excessive adhesiveness such as is apparently exhibited by both $r p f C$ and $\operatorname{cgs}_{s} A$ mutants enables acquisition and retention of cells within vectors but may inhibit their subsequent release that would be required for inoculation of new host plants.

Under conditions of low cell density within infested xylem vessels, DSF levels are expected to be low and $\operatorname{cgs} A$ expression would be elevated, thereby increasing cyclic di-GMP levels. Under conditions of locally high DSF concentrations that would be expected in larger cell assemblages, the opposite is true, and expression of adhesins would be elevated and promote a sessile and insect-transmissible lifestyle. These results indicate that, along with DSF-mediated cell-to-cell signaling, cyclic diGMP plays an important role in integrating extracellular signals and is involved as an intracellular signaling molecule in $X$. fastidiosa. The transition between the different lifestyles of plant and insect colonization apparently requires the modulation and fine tuning of cell-to-cell signaling and integration of cell-to-cell signaling into intracellular signaling system that is mediated by cyclic di-GMP.

\section{MATERIALS AND METHODS}

The $X$. fastidiosa strain Temecula was used for all experiments (van Sluys et al. 2003). Unless noted otherwise, $X$. fastidiosa cells were grown on PWG solid medium at $28^{\circ} \mathrm{C}$ (Hill and Purcell 1995).

\section{Construction of $X$. fastidiosa cgsA (PD0279) mutants.}

cgsA mutants of $X$. fastidiosa were obtained by transposon mutagenesis and allelic exchange. The cgsA gene (PD0279) was amplified from genomic DNA of $X$. fastidiosa Temecula using primers CGMP-F1 SacI: GCGAGCTCTTGCATCTTAA GTGTGTGGAGG and CGMP-R1 SacI: GCGAGCTCTTACA TCTCAGTACTGACCCGATC. The amplified fragment was cut with SacI and ligated to pUC19 (Yanisch et al. 1985) to obtain pSC19. Plasmid pSC19 was mutagenized in in vitro transposome using EZ::Tn5TM<Kan-2> (Epicentre, Madison, WI, U.S.A.) according to the manufacturer's instructions. All molecular biology protocols were done as described by Sambrook and associates (1989). The presence of a transposon insertion in the inserts was verified by PCR and their location determined by sequencing. Plasmids pSC20 and pSC21 were selected as having single transposon insertions at the 206th and 246th codon of $\operatorname{cgs} A$. PCR amplifications were performed with Pfu polymerase (Stratagene La Jolla, CA, U.S.A.) according to the manufacturer's instructions. pSC20 and pSC21 were electroporated into $X$. fastidiosa, and transformants selected on PWG plates containing kanamycin $(30 \mu \mathrm{g} / \mathrm{ml})$ as described by Newman and associates (2003). The disruption of the $\operatorname{cgs} A$ locus in allelic-exchange mutants was confirmed by sequencing and PCR (data not shown) and the $\operatorname{cgs} A$ mutant strains were designated $\mathrm{Cgs} 20$ and $\mathrm{Cgs} 21$.

Complementation of $\operatorname{cgs} A$ mutants with the wild-type gene.

The wild-type $\operatorname{cgs} A$ gene along with 500 bp of upstream sequence was amplified from wild-type $X$. fastidiosa Temecula using primers GGDEF-F SacI: GCGAGCTCAATGATCGAA TTCGGAAGGCTTGCA and GGDEF-R XbaI: GCTCTAGA TAGACATTCGCGACCTGACAAAACCACTCC. The amplified fragment was cut with $\mathrm{Xba \textrm {I }}$ and $\mathrm{SacI}$ and was ligated to XbaI-SacI-digested broad-host-range plasmid pBRR-5 (Kovach et al. 1995) to obtain pSC22. The complementing plasmid pSC22 and the empty vector pBRR-5 (pSC23) were introduced into Cgs20 by electroporation (Newman et al. 2003) and selected for gentamicin resistance (encoded by pBRR-5; on PWG plates containing gentamicin at $5 \mu \mathrm{g} / \mathrm{ml}$ ). The transformants were checked for the presence of the complementing plasmid and the empty vector by PCR amplification of both the gentamicin resistance cassette and the wild-type $\operatorname{cgs} A$ gene in $\mathrm{Cgs} 20(\mathrm{pSC} 22)$ and the presence of only the gentamicin resistance cassette from $\mathrm{Cgs} 20$ (pSC23) (pBRR-5 empty vector).

\section{Static biofilm formation assay.}

$X$. fastidiosa cells were collected with a loop by scraping plates and were resuspended in PWG liquid media. Approximately $10^{6}$ cells $/ \mathrm{ml}$ were suspended in $5 \mathrm{ml}$ of PW and aliquoted in 12-well polystyrene culture plates. The culture plates were incubated for 2 days at $28^{\circ} \mathrm{C}$ without shaking. After 2 days of incubation, the medium was discarded and the wells washed with double-distilled water (DDW) to remove planktonic and loosely attached cells. Biofilm formation was monitored by staining the remaining cells with $1 \%$ crystal violet for $10 \mathrm{~min}$ at room temperature. Excess crystal violet stain was removed by washing the wells with DDW. Crystal violet bound to the attached cells was solubilized with $1 \mathrm{ml}$ of $90 \%$ ethanol and quantified by measuring the absorbance at $570 \mathrm{~nm}$. Eight biological replicates were used. One-way ANOVA followed by the Tukey test was used to compare strains $(P=0.01)$.

\section{EPS quantification.}

EPS was immunologically quantified following previously published protocols (Killiny and Almeida 2009b). Two-way ANOVA followed by the Tukey test was used to compare strains and the effect of cell washing $(P=0.01) . X$. fastidiosa cells grown on PWG were also blotted onto dry nitrocellulose filters; the lifted prints were stained with $1 \%$ (vol/vol) of the glucan-specific dye (Murray et al. 1994) Alcian blue 8GX (Sigma-Aldrich) in 3\% acetic acid for $15 \mathrm{~min}$ and rinsed once with $3 \%$ acetic acid.

\section{Expression analysis by RT-PCR.}

Quantification of transcript abundance was performed as previously published (Chatterjee et al. 2008a and b; Killiny and Almeida 2009a and b). Transcript abundance was determined as the mean of three independent biological replicates, each of which was repeated three times.

\section{Electron microscopy.}

$X$. fastidiosa cells were prepared for scanning electron microscopy by fixation in $2 \%$ glutaraldehyde in $0.1 \mathrm{M}$ sodium cacodylate, $\mathrm{pH} 7.2$, then rinsed and post fixed in $1 \%$ osmium tetroxide at $4^{\circ} \mathrm{C}$ for $2 \mathrm{~h}$, after which they were rinsed, dehydrated, critical-point dried, and sputter coated with gold. Mi- 
crographs were taken with a Hitachi S-5000 Scanning electron microscope. For transmission electron microscopy, cells were obtained by scraping the surface of PWG plates. Cells deposited on Formvar-coated grids were negatively stained with $0.1 \%$ phosphotungstic acid. Micrographs were taken with an FEI Tecnai 12 transmission electron microscope. This work was performed at the University of California-Berkeley Electron Microscope Lab.

\section{Pathogenicity assays.}

Greenhouse-grown Vitis vinifera 'Cabernet sauvignon' grapevines (12 to 14 plants per replicate block) were mechanically inoculated using standard procedures (Hill and Purcell 1995). The number of symptomatic leaves distal to a point two nodes from the inoculation site was noted weekly after inoculation. ANOVA showed no significant effect of block $\left(\mathrm{F}_{1,75}=0.4 ; P=\right.$ $0.527)$; thus, blocks were combined for the analysis. One-way ANOVA followed by the Tukey test was used to compare strains $(P=0.05)$.

\section{Insect transmission.}

Insect transmission was assessed as described previously by Killiny and Almeida (2009a). Briefly, adults of Graphocephala atropunctata (Signoret) (blue-green sharpshooter; Hemiptera: Cicadellidae) were collected on riparian vegetation near the Russian River at Guerneville, CA, U.S.A.. Insects were maintained in the greenhouse on sweet basil and nymphs were transferred to healthy basil plants. Source plants were mechanically inoculated with either the wild type or one of the two mutants and, 3 months later, $X$. fastidiosa cells were cultivated from plants to insure that plants were infected (Almeida and Purcell 2003). Immunocapture DNA separation followed by PCR with primers RST31 and RST33 (Minsavage et al. 1994), as described by (Shapland et al. 2006), was also performed to confirm the cultivation results. To test whether the second-generation adult insects used were free from any preexisting $X$. fastidiosa, leafhoppers were caged first on healthy grape plants for 4 days to determine if any of these individuals transmitted $X$. fastidiosa; none were infected. Four adult $G$. atropunctata were caged on each infected source plant for a 4-day acquisition access period to acquire $X$. fastidios $a$. The four insects were then divided into groups of two individuals and transferred to healthy seedlings for a 4-day inoculation access period. Ten replicates were performed for each strain. Plants were subsequently maintained in a greenhouse for 3 months. $X$. fastidiosa cells were then detected by cultivation and immunocapture PCR from plants to determine the transmission rate. The number of infected plants was compared among the three $X$. fastidios $a$ strains tested using a two-by-three contingency table analysis $(P=$ $0.05)$. Follow-up pairwise Fisher exact tests were used to compare the control with Cgs20 and the control with Cgs21 $(P=$ $0.025)$. To quantify $X$. fastidiosa populations in vectors, cells were cultured from individual insect heads; after surface sterilization, heads were macerated in $100 \mu$ of succinato citrate phosphate buffer (Hilland and Purcell 1995) and a dilution was plated on PWG medium with or without kanamycin. One-way ANOVA was performed on log-transformed estimates of cell numbers obtained from each insect head.

\section{ACKNOWLEDGMENTS}

We thank B. C. Kirkpatrick (University of California-Davis) for providing anti-EPS antibody and sharing the protocol for EPS estimation by enzyme-linked immunosorbent assay, R. Koutsoukis for technical assistance, and B. Rotz for assistance in maintaining plants in the greenhouse. This study was supported by the California Department of Food and Agriculture, Pierce's Disease and Glassy-winged Sharpshooter Research Board.

\section{LITERATURE CITED}

Almeida, R. P. P., and Purcell, A. H. 2003. Transmission of Xylella fastidiosa to grapevines by Homalodisca coagulata (Hemiptera, Cicadellidae). J. Econ. Entomol. 96:264-271.

Andrade, M. O., Alegria, M. C., Guzzo, C. R., Docena, C., Rosa, M. C. P., Ramos, C. H. I., and Farah, C. S. 2006. The HD-GYP domain of RpfG mediates a direct linkage between the Rpf quorum-sensing pathway and a subset of diguanylate cyclase proteins in the phytopathogen Xanthomonas axonopodis pv. citri. Mol. Microbiol. 62:537-551.

Bobrov, A. G., Kirillina, O., and Perry, R. D. 2005. The phosphodiesterase activity of the HmsP EAL domain is required for negative regulation of biofilm formation in Yersinia pestis. FEMS (Fed. Eur. Microbiol. Soc.) Microbiol. Lett. 247:123-130.

Camilli, A., and Bassler, B. L. 2006. Bacterial small molecule signaling pathways. Science 311:1113-1116.

Chan, C., Paul, R., Samoray, D., Amiot, N. C., Giese, B., Jenal, U., and Schirmer, T. 2004. Structural basis of activity and allosteric control of diguanylate cyclase. Proc. Natl. Acad. Sci. U.S.A. 101:17084-17089.

Chatterjee, S., Almeida, R. P. P., and Lindow. S. E. 2008a. Living in two worlds: The plant and insect lifestyles of Xylella fastidiosa. Annu. Rev. Phytopathol. 46:243-271.

Chatterjee, S., Newman, K. L., and Lindow S. E. 2008b. Cell-to-cell signaling in Xylella fastidiosa suppresses movement and xylem vessel colonization in grape. Mol. Plant-Microbe Interact. 21:1309-1315.

Chatterjee, S., Wistrom, C., and Lindow, S. E. 2008c. A cell-cell signaling sensor is required for virulence and insect transmission of Xylella fastidiosa. Proc. Natl. Acad. Sci. U.S.A. 105:2670-2675.

D’Argenio D. A., and Miller S. I. 2004. Cyclic di-GMP as a bacterial second messenger. Microbiology 150:2497-2502.

Dow, J. M., Crossman, L., Findlay, K., He, Y. Q., Feng, J. X., and Tang, J. L. 2003. Biofilm dispersal in Xanthomonas campestris is controlled by cell-cell signaling and is required for full virulence to plants. Proc. Natl. Acad. Sci. U.S.A. 100:10995-11000.

Dow, J. M., Fouhy, Y., Lucey, J. F., and Ryan R. P. 2006. The HD-GYP domain, cyclic Di-GMP signaling, and bacterial virulence to plants. Mol. Plant-Microbe Interact.19:1378-1384.

Feil, H., Feil, W. S., and Lindow, S. E. 2007. Contribution of fimbrial and afimbrial adhesins of Xylella fastidiosa to attachment to surfaces and virulence to grape. Phytopathology 97:318-324.

Guilhabert, M. R., and Kirkpatrick, B. C. 2005. Identification of Xylella fastidiosa antivirulence genes: Hemagglutinin adhesins contribute to $X$ fastidiosa biofilm maturation and colonization and attenuate virulence. Mol. Plant-Microbe Interact. 18:856-868.

He, Y. W., Wang, C., Zhou, L., Song, H., Dow, J. M., and Zhang, L. H. 2006. Dual signaling functions of the hybrid sensor kinase RpfC of Xanthomonas campestris involved either phosphorelay or receiver domain-protein interaction. J. Biol. Chem. 281:33414-33421.

Hill, B. L., and Purcell, A. H. 1995. Multiplication and movement of $X y$ lella fastidiosa within grapevine and four other plants. Phytopathology 85:1368-1372.

Hoffman, L. R., D’Argenio, A. D., MacCoss, M. J., Zhang, Z., Jones, R. A., and Miller, S. I. 2005. Aminoglycoside antibiotics induce bacterial biofilm formation. Nature 436:1171-1175.

Hopkins, D. L., and Purcell, A. H. 2002. Xylella fastidiosa: Cause of Pierce's disease of grapevine and other emergent diseases. Plant Dis. 86:1056-1066.

Jenal, U., and Malone, J. 2006. Mechanisms of cyclic di-GMP signaling in bacteria. Annu. Rev. Genet. 40:385-407.

Killiny, N and Almeida, R. P. 2009a Xylella fastidiosa afimbrial adhesins mediate cell transmission to plants by leafhopper vectors. Appl. Environ. Microbiol. 75:521-528.

Killiny, N and Almeida, R. P. 2009b. Host structural carbohydrate induces vector transmission of a bacterial plant pathogen. Proc. Natl. Acad. Sci. U.S.A. 106:22416-22420.

Kovach, M. E., Elzer, P. H., Hill, D. S., Robertson, G. T., Farris, M. A., Roop, R. M., and Peterson, K. M. 1995. Four new derivatives of broad host range cloning vector pBRR1MCS, carrying different antibiotic resistance cassettes. Gene 166:175-176.

Lim, B. Beyhan, S. Meir, J., and Yildiz, F. H. 2006. Cyclic-diGMP signal transduction systems in Vibrio cholerae: Modulation of rugosity and biofilm formation. Mol. Microbiol. 60:331-48

Meng, Y., Li, Y., Galvani, C. D., Hao, G., Turner, J. N., Burr, T. J., and Hoch, H. C. 2005. Upstream migration of Xylella fastidiosa via pilusdriven twitching motility. J. Bacteriol. 187:5560-5567.

Minsavage, G. V., Thompson, C. M., Hopkins, D. L., Leite, R. M. V. B. C., and Stall, R. E. 1994. Development of a polymerase chain reaction protocol for detection of Xylella fastidiosa in plant tissue. Phytopathology 84:456-461.

Murray, R. G. E., Doetsch, R. N., and Robinow, C. F. 1994. Determinative 
and cytological light microscopy. Pages 21-41 in: Manual of Methods for General Bacteriology. P. Gerhardt, R.G.E. Murray, W. A. Wood, and N. R. Krieg, eds. American Society for Microbiology Press, Washington, D.C.

Newman, K. L., Almeida, R. P. P., Purcell, A. H., and Lindow, S. E. 2003. Use of a green fluorescent strain for analysis of Xylella fastidiosa colonization of Vitis vinifera. Appl. Environ. Microbiol. 69:7319-7327.

Newman, K. L., Almeida, R. P. P., Purcell, A. H., and Lindow, S. E. 2004 Cell-cell signaling controls Xylella fastidiosa interactions with both insects and plants. Proc. Natl. Acad. Sci. U.S.A. 101:1737-1742.

Redak, R. A., Purcell, A. H., Lopes, J. R. S., Blua, M. J., Mizell, R. F., III, and Andersen, P. C. 2004. The biology of xylem fluid-feeding insect vectors of Xylella fastidiosa and their relation to disease epidemiology. Annu. Rev. Entomol. 49:243-270.

Romling, U., and Amikam, D. 2006. Cyclic di-GMP as a second messenger. Curr. Opin. Microbiol. 9:218-228.

Romling, U., Gomelsky, M., and Galperin, M. Y. 2005. C-di-GMP: The dawning of a novel bacterial signaling system. Mol. Microbiol. 57:629639.

Roper, M. C., Greve, L. C., Labavitch, J. M., and Kirkpatrick, B. C. 2007. Detection and visualization of an exopolysaccaride produced by Xylella fastidiosa in vitro and in planta. Appl. Environ. Microbiol. 73:72527258.

Ryan, R. P., Fouhy, Y., Lucey, J. F., Crossman, L. C., Spiro, S., He, Y. W., Zhang, L. H., Heeb, S., Camara, M., Williams, P., and Dow, J. M. 2006a. Cell-cell signaling in Xanthomonas campestris involves an HDGYP domain protein that functions in cyclic di-GMP turnover. Proc. Natl. Acad. Sci. U.S.A. 103:6712-6717.

Ryan, R. P., Fouhy, Y., Lucey, J. F., and Dow, J. M. 2006b. Cyclic di-GMP signaling in bacteria: Recent advances and new puzzles. J. Bacteriol. 188:8327-8334.

Ryan, R. P., McCarthy, Y., Andrade, M., Farah, C. S., Armitage, J. P. and Dow, J. M. 2010. Cell-cell signal-dependent dynamic interactions between HD-GYP and GGDEF domain proteins mediate virulence in Xanthomonas campestris. Proc. Antl. Acad. Sci U.S.A. 107:5989-5994.

Sambrook, J., Fritsch, E. F., and Maniatis, T. A. 1989. Molecular Cloning: A Laboratory Manual, 2nd ed. Cold Spring Harbor Laboratory Press, Cold Spring Harbor, NY, U.S.A.
Simm, R., Morr, M., Kader, A., Nimtz, M., and Romling, U. 2004 GGDEF and EAL domains inversely regulate cyclic di-GMP levels and transition from sessility to motility. Mol. Microbiol. 53:1123-1134.

Shapland, E. B., Daane, K. M., Yokota, G, Y., Wistrom, C., Connell, J. H., Duncan, R. A., and Viveros, M. A. 2006. Ground vegetation survey for Xylella fastidiosa in California almond orchards. Plant Dis. 90:905909.

Solano, C., García, B., Latasa, C., Arana, A., Zorraquino, V., Valle, J., Casals, J., Pedroso, E. and Las, I. 2009. Genetic reductionist approach for dissecting individual roles of GGDEF proteins within the c-di-GMP signaling network in Salmonella. Proc. Natl. Acad. Sci. U.S.A. 106:79978002

Souza, L. C. A., Wulff, N. A., Gaurivaud, P., Mariano, A. G., Virgilio, A. C. D. Azevedo, J. L., and Monteiro, P. B.2006. Disruption of Xylella fastidiosa $\mathrm{CVC}$ gumB and gumF genes affect biofilm formation without a detectable difference in exopolysaccharide production. FEMS (Fed. Eur. Microbiol. Soc.) Microbiol. Lett. 257:236-242.

Tamayo, R., Pratt, J. T., and Camilli, A. 2007. Roles of cyclic diguanylate in the regulation of bacterial pathogenesis. Annu. Rev. Microbiol. 61:131-148.

Van Sluys, M. A., de Oliveira, M. C., Monteiro-Vitorello, C. B., Miyaki, C. Y., Furlan, L. R. Camargo, L. E., da Silva, A. C., Moon, D. H., Takita, M A., Lemos, E. G., Machado, M. A., Ferro, M. I., da Silva, F. R., Goldman, M. H., Goldman, G.H., Lemos, M. V., El-Dorry, H., Tsai, S. M., Carrer, H., Carraro, D. M., de Oliveira, R. C., Nunes, L. R., Siqueira, W. J., Coutinho, L.L., Kimura, E. T., Ferro, E. S., Harakava, R., Kuramae, E. E. Marino, C. L., Giglioti, E., Abreu, I. L., Alves, L. M., do Amaral, A. M., Baia, G. S., Blanco, S. R., Brito, M. S., Cannavan, F. S., Celestino, A. V., da Cunha, A. F., Fenille, R. C., Ferro, J. A., Formighieri, E. F., Kishi, L. T., Leoni, S. G., Oliveira, A. R., Rosa, V. E., Jr., Sassaki, F. T., Sena, J.A., de Souza, A. A., Truffi, D., Tsukumo, F., Yanai, G. M., Zaros, L. G. Civerolo, E.L., Simpson, A. J., Almeida, N. F., Jr., and Setubal, J. C. 2003 Comparative analysis of the complete genome sequences of Pierce's disease and citrus variegated chlorosis strain of Xylella fastidiosa. J. Bacteriol. 185:1018-1026.

Yanisch-Perron, C., Vieira, J., and Messing, J. 1985. Improved M13 phage cloning vectors and host strains: Nucleotide sequences of the M13mpl8 and pUC19 vectors. Gene 33:103-119. 